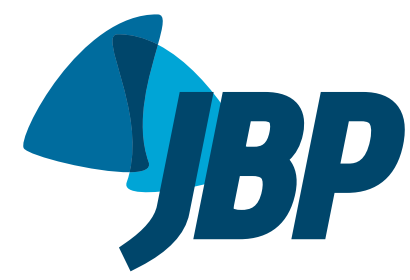

CLINICAL SCENARIO

A 69-year-old White female patient was suspected of having COPD and was therefore referred for functional

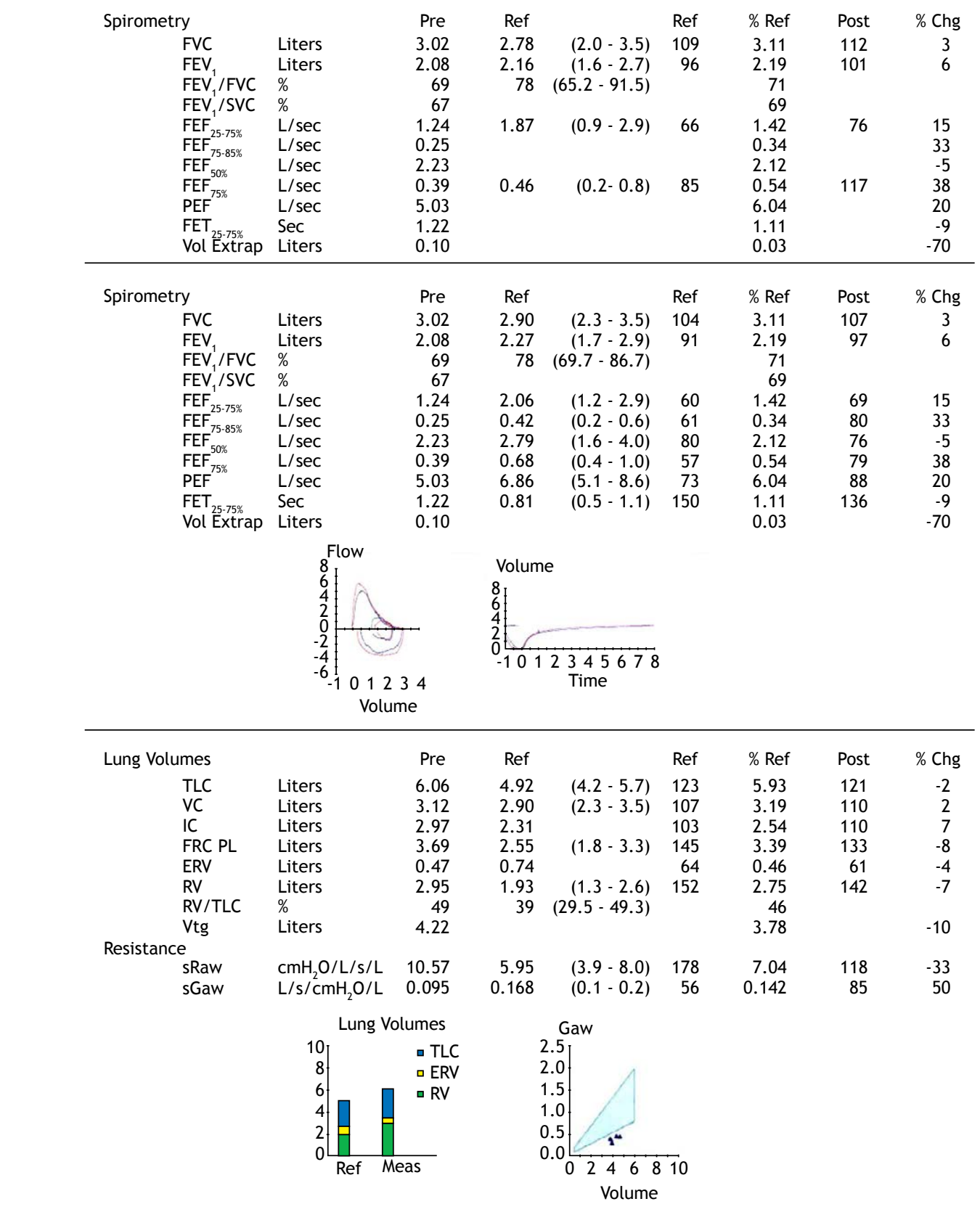

evaluation. She reported a 4-year history of morning cough and sputum production, as well as dyspnea when hurrying on level ground or walking up a slight incline. She reported no wheezing attacks. The patient was a former

\section{The importance of appropriate reference values in patients suspected of having obstructive lung disease}

Carlos Alberto de Castro Pereira ${ }^{1, a}$, Maria Raquel Soares ${ }^{1, b}$, Andréa Gimenez ${ }^{2, c}$

Figure 1. Functional values in patients suspected of having COPD, in comparison with the predicted values suggested by the Global Lung Function Initiative (in A) ${ }^{(1)}$ and the predicted values for spirometry and lung volumes in the Brazilian population (in B and C). ${ }^{(2)}$

1. Universidade Federal de São Paulo/Escola Paulista de Medicina, São Paulo (SP) Brasil.

2. Centro Diagnóstico Brasil, São Paulo (SP) Brasil.

a. (iD) http://orcid.org/0000-0002-0352-9589; b. (D) http://orcid.org/0000-0002-2242-2533; c. (D) http://orcid.org/0000-0002-5714-9530 
smoker (with a smoking history of 35 pack-years), and her body mass index was $27.3 \mathrm{~kg} / \mathrm{m}^{2}$.

\section{FUNCTIONAL ASSESSMENT}

The patient underwent spirometry, which was performed in accordance with acceptability and reproducibility criteria. Spirometry results and lung volumes were determined on the basis of reference values suggested by the Global Lung Function Initiative (GLI) in 2012(1) and reference values for the Brazilian population, ${ }^{(2)}$ and are shown in Figure 1.

When the GLI reference values were used, ${ }^{(1)}$ the $\mathrm{FEV}_{1} / \mathrm{FVC}$ ratio, $\mathrm{FEF}_{25-75 \%}$, and $\mathrm{FEF}_{75 \%}$ were found to be within the predicted range. When the reference equations for the Brazilian population were used, (2) the $\mathrm{FEV}_{1} / \mathrm{FVC}$ ratio and $\mathrm{FEF}_{75 \%}$ were found to be slightly reduced. The presence of airflow obstruction was confirmed by increased specific airway resistance, RV, and TLC. There were no significant changes in lung function parameters after administration of $400 \mu \mathrm{g}$ of bronchodilator via a metered dose inhaler.

\section{COMMENTARY}

In order to interpret pulmonary function test results correctly, it is critical to use appropriate reference values. Because numerous predicted value equations are available in the literature, reference values vary widely.

The GLI equations ${ }^{(1)}$ included a large number of individuals from many centers. The results obtained were influenced by several factors, including sample selection and the variety of measurement and quality control techniques, all of which made it difficult to aggregate the results across studies and increased the range of predicted values, with very low lower limits. For example, for a 65-year-old male who is $170 \mathrm{~cm}$ in height, the lower limit of normal is 0.70 when the reference values for the Brazilian population are used ${ }^{(2)}$ and 0.65 when the GLI reference values are used. ${ }^{(1)}$ For a 65-year-old female who is $165 \mathrm{~cm}$ in height, the lower limit of normal is 0.70 when the reference values for the Brazilian population are used ${ }^{(2)}$ and 0.66 when the GLI reference values are used. ${ }^{(3)}$ The Global Initiative for Chronic Obstructive Lung Disease maintains that airflow obstruction should be defined by an $\mathrm{FEV}_{1} / \mathrm{FVC}$ ratio of $<0.70$; not surprisingly, a recent study ${ }^{(4)}$ found that an $\mathrm{FEV}_{1} / \mathrm{FVC}$ ratio of $<0.70$ had better predictive value for long-term COPD-related hospitalization and mortality than did the lower limit of normal as defined by the GLI reference equations (i.e., $<0.70$ for middle-aged individuals and the elderly).

The same applies to the lower limits of normal for $\mathrm{FEF}_{25-75 \%}$ and $\mathrm{FEF}_{75 \%}$, mid- and end-expiratory flows being of no value in characterizing airflow limitation when the limits recommended by the $\mathrm{GLI}^{(1)}$ are used. ${ }^{(5)}$

In the study conducted in Brazil, (2) a small number of certified technicians supervised by the principal investigator throughout the study performed all tests at eight selected centers. Extensive efforts were made to meet acceptability and reproducibility criteria. In that study, ${ }^{(2)}$ in addition to $\mathrm{FEV}_{1}$ and $\mathrm{FVC}<0.15 \mathrm{~L}$, at least three peak flow values lower than the highest value by $<10 \%$ were required for acceptability. These criteria had not been used in previous studies.

\section{REFERENCES}

1. Quanjer PH, Stanojevic S, Cole TJ, Baur X, Hall GL, Culver BH, et al. Multi-ethnic reference values for spirometry for the 3-95-yr age range: the global lung function 2012 equations. Eur Respir J 2012;40(6):1324-43. https://doi.org/10.1183/09031936.00080312

2. Pereira CA, Sato T, Rodrigues SC. New reference values for forced spirometry in white adults in Brazil. J Bras Pneumol. 2007;33(4):397406. https://doi.org/10.1590/\$1806-37132007000400008

3. Pereira CA, Duarte AA, Gimenez A, Soares MR. Comparison between reference values for FVC, FEV1, and FEV1/FVC ratio in White adults in Brazil and those suggested by the Global Lung Function Initiative
2012. J Bras Pneumol. 2014;40(4):397-402. https://doi.org/10.1590/ S1806-37132014000400007

4. Bhatt SP, Balte PP, Schwartz JE, Cassano PA, Couper D, Jacobs DR $\mathrm{Jr}$, et al. Discriminative Accuracy of FEV1:FVC Thresholds for COPD Related Hospitalization and Mortality. JAMA. 2019;321(24):24382447. https://doi.org/10.1001/jama.2019.7233

5. Quanjer PH, Weiner DJ, Pretto JJ, Brazzale DJ, Boros PW Measurement of FEF25-75\% and FEF75\% does not contribute to clinical decision making. Eur Respir J. 2014;43(4):1051-8. https://doi. org/10.1183/09031936.00128113 